Discussion Paper No. 06-071

\title{
Success Breeds Success Locally: A Tale of Incubator Firms
}

Eren Inci

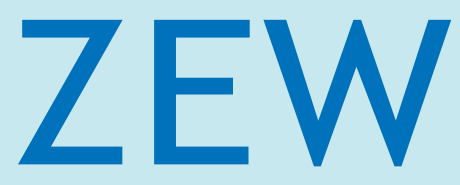

Zentrum für Europäische Wirtschaftsforschung $\mathrm{GmbH}$

Centre for European

Economic Research 
Discussion Paper No. 06-071

\title{
Success Breeds Success Locally: A Tale of Incubator Firms
}

\author{
Eren Inci
}

Download this ZEW Discussion Paper from our ftp server:

ftp://ftp.zew.de/pub/zew-docs/dp/dp06071.pdf

Die Discussion Papers dienen einer möglichst schnellen Verbreitung von neueren Forschungsarbeiten des ZEW. Die Beiträge liegen in alleiniger Verantwortung der Autoren und stellen nicht notwendigerweise die Meinung des ZEW dar.

Discussion Papers are intended to make results of ZEW research promptly available to other economists in order to encourage discussion and suggestions for revisions. The authors are solely responsible for the contents which do not necessarily represent the opinion of the ZEW. 


\section{Non-technical summary of Success Breeds Success Locally: A Tale of Incubator Firms by Eren Inci}

This paper models the pre-establishment period of start-ups. Starting and expanding a business is not easy in a world of tough competition. It is well-evidenced all over the world that many startups end up with failures within the first couple of years of business. This suggests that there must be alternative avenues taken by the firms in successful industrial locations that have led them to experience less frequent business failures. One effective such avenue is to form informal networks. When they are developing their innovative ideas and preparing business strategies, potential entrepreneurs not only interact with each other and established firms but also they get help from established firms in obtaining finance. This paper analyzes how these informal networks form, and then provides the outcome of the market in the presence of these networks to see if they lead to better outcomes for the network members and for the society.

I analyze the effects of ties between start-ups and established firms in geographic proximities, and their relationships with the local financiers and banks. On the one hand, for better chances of survival, new firms usually need enough liquidity, better technical expertise in production and business (such as pricing and marketing). On the other hand, successful regional economies can often be tracked down to one or two hub firms which form fertile environments that induce constant creation of new firms. These hub firms act as seedbeds for new ideas or start-ups by sponsoring the innovative activities of related individuals. They are the places where potential entrepreneurs meet when they are developing their marketable ideas. They advise related firms in their baby stages to prevent premature developments. These relationships usually end up with financial collaborations. Hub firms have good relationships with local financiers which they can use in finding finance for the projects of entrepreneurs in their networks. They may also invest in these start-ups if they see any exploitable profit opportunities.

Explaining why a hub firm form such a network is not that trivial. In the presence of asymmetric information between the entrepreneurs and financiers, the market overvalues the start-ups with low success probabilities and undervalues the start-ups with high success probabilities. When the hub firm shares its views about the entrepreneurs in its network with the local financiers, the level of under and over-valuation is altered for the network entrepreneurs. As is shown in the paper, it sometimes makes both parties better off and sometimes only the start-ups with high success probabilities better off. When both parties are able to provide side payments to the hub firm, it is obvious that there are incentives for the hub firm to communicate its views to the local financiers in the former case since both parties are willing to provide side payments to the hub firm to induce it to do so. More importantly, even when two parties have conflicting interest, the side payments that the start-ups with the high success probabilities are willing to and able to offer to the hub firm to induce it to not to communicate its ideas to the local financiers is higher than that of the start-ups with low success probabilities to induce it to not to do so. This suggests that there are certain incentives for the hub firm to decrease the information gap between the entrepreneurs and the local. One potential problem in this is that the hub firm might not honestly share its views about the potential entrepreneurs in its networks with the local financiers. Nonetheless, the reliability is guaranteed whenever hub firms buy sufficiently large shares of the portfolio of start-ups in their networks that it claims to be promising which is consistent with what is observed in the early stages of industrial districts. 


\title{
SUCCESS BREEDS SUCCESS LOCALLY: A TALE OF INCUBATOR FIRMS
}

\author{
Eren Inci* \\ Boston College
}

October 2006

ZEW Discussion Paper No. 06-071

\begin{abstract}
This paper focuses on the pre-establishment period of start-ups in industrial districts. The industrial architecture is what I call a "rationed agglomeration" in which some entrepreneurs gather around an established firm while other entrepreneurs in the same business stand alone. In a rationed agglomeration, I analyze the effects of relations between established firms, network entrepreneurs, and local financiers on the market prices of loans. I show that such relations improve the match of capital to ideas in the network even though the overall distribution of capital to ideas remains unchanged. This suggests that success breeds success in the networks of established firms. The existence of networks overturns the claim that there are no motives to engage in information gathering in a simple market regime with information asymmetries. In particular, I show that there are market incentives for established firms to decrease the information gap between network entrepreneurs and local financiers.
\end{abstract}

Keywords: agglomeration; entrepreneur; dispersion; innovation; local financiers; networks; regional economies; project financing; signaling; start-up

JEL Classification: D82; G20; R12; L26

\footnotetext{
${ }^{*}$ Tel.: 1-617-552-3670; fax: 1-617-552-2308. Address: Boston College, Department of Economics, 140 Commonwealth Avenue, Chestnut Hill MA 02467-3806 USA. E-mail address: inci@bc.edu. This paper was initiated while I was visiting the Industrial Economics and International Management Department of the Center for European Economic Research (ZEW) in 2006. I am grateful to their hospitality and financial support. I have greatly benefited from discussions with James Anderson, Richard Arnott, Georg Licht, and participants of the Cambridge-MIT Institute's Workshop on Regional Innovation. All errors are mine.
} 
We [...] show how Cleveland's initial locational advantages were magnified, perhaps serendipitously, by a small number of successful enterprises that both exemplified the wealth-creation possibilities of these new technologies and served as hubs of overlapping networks of inventors and financiers. Focusing on one of the most important of these hubs - the Brush Electric Company - we show how such enterprises served multiple functions for the inventors who gathered around them. On the one hand, they were places that fostered technological crossfertilization and the exchange of ideas about how to solve particularly difficult problems. On the other hand, they were places where the technological community could pass on — validate - promising ideas and thus perform a useful vetting function for local capitalists.

Lamoreaux, Levenstein, and Sokoloff (2004, pg. 2)

\section{Introduction}

One important economic phenomenon is that geographic proximity creates positive externalities among firms. Sometimes these are physical spillovers in the form of low transportation costs (Krugman, 1991); sometimes they are intellectual spillovers which are more pronounced among firms that are close to each other (Glaeser et al., 1992). In general, the main reason for concentration of firms near each other is the existence of some sort of increasing returns to scale. This paper focuses on a different aspect of agglomeration economies. Starting and expanding a business is not easy in a world of intense competition. It is well-documented world-wide that many start-ups end up as failures within the first couple of years of starting business (see, for example, Bates (2005), Brandt (2004), Headd (2003) or OECD (2006) for recent evidence). ${ }^{1}$ This suggests the firms in successful industrial locations must have taken alternative avenues that led them to experience less frequent business failures. One such effective avenue is to form informal networks to overcome the stigma of failure. When they are developing ideas and preparing business strategies, potential entrepreneurs not only interact with each other and established firms but they also get help from the established firms in obtaining funding. This paper analyzes how these nonmarket institutions (informal networks) form, and then derives the outcome of the market in the presence of these nonmarket institutions to see if they lead to better outcomes for the network members and for society in general.

I analyze the effects of ties between start-ups and established firms in close geographic proximities, and their relationships with the local financiers and banks. On one side, for better chances of survival, new firms need enough liquidity, and better technical expertise in production and business plans (such as pricing and marketing). On the other side, the source of successful regional economies can often be tracked down to one or two hub firms which form fertile environments that induce the constant creation of new firms. These hub firms usually breed new firms with lower risk of failure by improving the match of capital to ideas in their networks, and act as seedbeds for new ideas or start-ups by sponsoring the innovative activities of related individuals. These are the places where potential entrepreneurs meet when they are developing their

\footnotetext{
${ }^{1}$ There could be successful and unsuccessful closures. Even with that distinction, there is still a significant number of failures: between 30 to 40 percent of firms experience unsuccessful closures within the first couple of years of business.
} 
marketable ideas. They advise related firms in their early stages in order to prevent premature developments that could end up in failures. These relationships usually end up in financial collaborations since it is known that most business failures are the result of lack of access to either sufficient or cheap enough loans. It is well-documented by Petersen and Rajan (1994) that ties between firms and their creditors are very important for the availability and cost of funds. The hub firms have good relationships with local financiers which they can use in finding finance for the projects of entrepreneurs in their networks. They may also invest in these start-ups if they see any exploitable profit opportunities. This process results in higher success probabilities in the network.

The analysis boils down to a model of pre-establishment period of start-ups. The stepping stones of the model are based on the work of Lamoreaux, Levenstein, and Sokoloff (2004), who provide a wonderful historical case study of financing innovation in Cleveland, Ohio in the ninetieth century, which was much like the Silicon Valley of its time, and the role of networks in generating and financing innovative ideas. They focus particularly on the Brush Electric Company, the inventors gathered around it, and the firms that were somehow brought to life in the network of Brush Electric Company. Their paper can also be viewed as the empirical support for the model presented here. I quote passages from this paper wherever necessary to elucidate the assumptions and results.

The details of the model and the summary of findings are as follows. The pre-establishment period of start-ups is assumed to have two phases. In phase I, potential entrepreneurs collect information about their subject matter. They not only develop innovative ideas but also consider how to market and sell these ideas. They have two options in this phase: they can either stand alone and develop their innovative ideas and business strategies by themselves or they can join the network of a hub firm that provides a collaborative environment with other would-be entrepreneurs. Phase I is similar to the R\&D game presented in Inci (2005) with some differences. If an entrepreneur stands alone, his benefit results from his own effort (which has a deterministic and a random component) and the knowledge that spills over from the other nearby entrepreneurs. The degree of knowledge spillover is higher among entrepreneurs who are in the same network, but the benefit that derives from their own effort is still the same no matter whether they are in or outside the network. However, there are costs to joining a network.

It turns out that, as a result of network externalities, any stable equilibrium has to be a corner outcome. That is, either all entrepreneurs prefer to join the network or they all stand alone. The reason for this is that an entrepreneur finds it beneficial to join a network only if sufficient numbers of others are doing so. Nonetheless a hub firm cannot allow just anyone to join its network, which suggests that there will be some sort of rationing process involved in joining the network. This is why we observe firms that are related to each other as well as some others that stand alone in the same industrial district. I call this industrial architecture a rationed agglomeration. At the end of phase I, the random part of the individual benefit is drawn by the nature, and thus, the types of projects are determined. I assume for simplicity that there can only be two outcomes: good or bad. Hence, there will be entrepreneurs with projects of high and low success probability both in and outside the network. However, I assume that those with a good drawing will be high in number in the network than outside the network.

Phase II of the pre-establishment period of start-ups involves seeking funding for the business projects that are already in hand. In this stage, entrepreneurs have already es- 
tablished their networks, come up with their innovative ideas, and prepared the business plans associated with these ideas. Phase II, therefore, focuses on a rationed agglomeration in which there are more high-success probability projects in the network than outside the network. This phase is a variation of the project financing game of Inci (2006). However, the population is now composed of two layers, network entrepreneurs and stand-alone entrepreneurs. It is assumed that all projects are worthy even though some of them have better chances of survival. Efficiency requires that all of these projects should be financed. So credit rationing is not an issue in this model.

Under normal conditions, entrepreneurs apply for bank loans to finance their projects. There are, however, two important assumptions of the model. First, a hub firm has a belief about the project type of an entrepreneur which may or may not be correct for this particular entrepreneur, but its beliefs on average are informative due to its repeated relationship with entrepreneurs in phase I. It can make useful judgments simply because it has long years of business experience, although it may still make incorrect judgments. The network membership of those who are believed to have low-success probability projects expires automatically. Second, a hub firm has close relationships with local financiers to whom it can convey its beliefs about the entrepreneurs in its network. This channel can decrease the information gap between the network entrepreneurs and local financiers. Then, if the local financiers trust the information they get from the hub firm, they will provide cheaper loans to those who are labeled as good by the hub firm, and they decline the applications of those who are labeled as bad for privileged loans. The declined group as stand-alone entrepreneurs may then apply for regular loans that are readily available in the credit market either from the banks or local financiers. Being aware of these relations in the market, banks would then change their beliefs about the distribution of types in the population since a better sample of entrepreneurs are financed by the local financiers with cheaper loans due to their better information about this sample. This means that the price of loans is higher for the stand-alone entrepreneurs and for those who are declined for privileged loans. Therefore, the hub firm's signaling improves the credit market outcome of those who stay in the network and worsens the outcome of the rest.

One other important point is that there will still be the same number of high and low success probability projects in the region since the lenders prefer to finance both types of projects. This suggests that the only positive effect of the network comes from phase I, in creating more high success probability projects. In phase II, networks may improve their possible outcomes in the market; however, this may not be useful for the society in general since the quality composition of entrepreneurs are still the same. Arnott and Stiglitz (1991) show that nonmarket institutions may be dysfunctional when they are not informationally advantaged over the market - which is also the case in this paper if the signals from the hub firm are not informative. Beyond that, what the model presented here suggests is that even in the case in which the nonmarket institution is informationally advantaged (e.g.; relationships generate useful information), the outcome may not be useful for the society at all. Hub-signaling can create islands of related entrepreneurs that experience less frequent business failures and enjoy cheaper loans even though the overall failure rate in the population remains unchanged.

In their empirical paper, Petersen and Rajan (1994) find that banking relationships are valuable, although they conclude that these relationships appear to operate more 
through quantities than prices. ${ }^{2}$ However, they implicitly assume that the decreases in the cost of loanable funds are passed on to the borrowers, which is not necessarily to be the case in the presence of monopolistic power over information. This is consistent with the results derived here. Suppose there is only one local financier that has access to the signals of the hub firm. Since it has monopoly power on this information it knows that the default rate in its loan applicant pool will now be lower, but it does not need to reflect this change to the borrowers. In that case, it can still finance the same entrepreneurs with the same loan prices available in the market and make positive profits.

When there is pooling equilibrium in the credit markets - which is the case in this paper - the market overvalues the start-ups with low success probabilities and undervalues the start-ups with high success probabilities. The existence of networks may change this situation. I show that hub-signaling always make entrepreneurs with high success probability better off by decreasing the level of market's undervaluation of their startups. However, entrepreneurs with low success probability projects prefer hub-signaling either when the network is large enough or when the signals are not very informative. In such a case, both parties prefer hub-signaling, and side payments promised by them can be sufficient incentives for the hub firm to organize hub-signaling. However, when the networks are small or the signals are sufficiently informative, owners of the low success probability start-ups prefer the status quo while the owners of the high success probability start-ups prefer hub-signaling. Yet, I show that the maximum amount of side payments that the latter group is willing and able to pay to the hub firm is higher than that of the former group. This means that there are certain incentives for the hub firm to form the hub-signaling mechanism. This result can be contrasted with the nonexistence of a rational expectation equilibrium in Campbell and Kracaw (1980), and as I show in this paper, it can be fairly generalized to a case in which extracting the information about start-ups is costly for the hub firm.

I assume throughout the paper that the hub firm conveys its signals honestly to the local financiers. There are a couple of reasons to believe this. First, the hub firm may have some repeated financial relationship with the local financiers. So, it may not be in its best interest in the long run to act dishonestly. Moreover, acting dishonestly may jeopardize its credibility in the market as well. Whenever the credibility of signals is a problem, local financiers may finance the start-ups if the hub firm is also investing in those projects. If the hub firm believes that the entrepreneurs it recommends will have better start-ups on average, it should be more than happy to invest in them. Section 5 shows that the signals of the hub firm are credible only if it has sufficiently large stakes in these start-ups. However, this can happen only when the hub firm has sufficient assets. Therefore, the established firms that can credibly organize hub-signaling should be the ones with deep pockets.

The paper is organized as follows. Section 2 sketches the pre-establishment period of start-ups, which has two phases. Phase I - the phase in which entrepreneurs work on

\footnotetext{
${ }^{2}$ I focus on relationships between start-ups and an already established firm which has relationships with local financiers. The relationship in Petersen and Rajan (1994) is between lenders and borrowers, not via a hub firm. The hub firm's ideas about the entrepreneur that it conveys to the lenders should be more credible than an entrepreneur's signaling of his own type. Moreover, Petersen and Rajan (1994) focus on already established firms whereas I focus on start-up firms for which the data cannot capture the relationship as the define it. They define the relationship as having at least one other financial service from the lender besides borrowing, such as depository services, factoring, or pension fund management.
} 
innovative ideas and prepare their business plans - is modeled in section 3. Entrepreneurs' network formation decisions and the resulting industrial architecture in the region are also discussed in this section. Phase II - the phase in which entrepreneurs apply for business loans - is modeled in section 4 . In this section, the canonical project financing equilibrium from banks is derived as a benchmark followed by the analysis of the role of established firms in entrepreneurs' loan applications to the local financiers. Section 5 discusses the incentive scheme for the hub firm to organize hub-signaling assumed in the previous sections. Costly signaling and the reliability of signals are also discussed here as extensions of the model. Section 6 concludes. An appendix contains some of the proofs.

\section{A model of pre-establishment period of start-ups}

I consider a simple model of a regional economy to model the pre-establishment period of start-ups. There are two phases in this period. The first phase is the idea generation stage in which potential entrepreneurs try to develop their business projects. This requires not only engaging in invention projects that might end up with an innovation with some economic value but also developing business plans such as pricing and marketing strategies. Section 3 models this phase where I try to explain why we observe different economic architectures across time and space. The focus of this part of the model is at the aggregate level of a regional economy and it tries to provide some insights on why there are some industrial districts where there is a number of firms in a network gathered around established firms at the same time there are some others standing alone in the same business matter. Basically, this part analyzes what I call a "rationed agglomeration" (partial agglomeration of start-ups around some established firms).

In the second phase, potential entrepreneurs have already come up with their business ideas which are presumably risky. They are now in a position to look for financing possibilities for their risky projects. As I argue in the introduction of the paper, the main obstacle in new firm formation is the relentless stigma of failure. Section 4 models this start-up financing game between entrepreneurs and lenders (banks and local financiers) in the presence of a rationed agglomeration around an established firm. I explain the role of this established firm in finding (possibly) cheaper finance to the potentially better entrepreneurs in its networks by conveying its beliefs about the quality of the projects of the would-be entrepreneurs in their networks to the local financiers.

What is below uses the words "entrepreneur", "firm", "inventor", "individual", and "agent" interchangeably. Doing so does not make much difference for my purpose since I track the flow of business project itself - and not its owners - at different times in its life cycle. In general, inventors come up with an innovative idea. Then, an entrepreneur - who may or may not be the same person with the inventor - carries out the project. Where it makes a difference at all, the payoff structure of the model implicitly takes into account the net effects of economic interactions among any parties in exchanging the business project with each other. I also use "entrepreneur" instead of "potential entrepreneur" at some places for brevity. This is harmless since there is no credit rationing in this model, and thus, all potential entrepreneurs will become entrepreneurs no matter what happens. 


\section{Phase I: innovative idea creation and business plans}

[... Inventors who were just starting their careers needed some [...] way to signal that their ideas were promising. Here Cleveland's industrial hubs played a critical role. Because they were collecting points for technological expertise, they served an important vetting function. Inventors seeking validation for their ideas gravitated to these hubs. So did business people in search of profitable investments. In this way, the networks that formed around innovative firms like Brush Electric and White Sewing Machine became engines of local economic development. They encouraged the geographic concentration both of technological creativity and of venture capital. They also matched inventors who had promising ideas with business people who possessed the managerial skills needed to transform these ideas into productive enterprises. (Lamoreaux, Levenstein, and Sokoloff, 2004, pg. 35)

Suppose there is a region at the beginning of the period that can become an industrial district if it experiences a constant formation of successful firms over time. What I have in mind is a would-be agglomeration at the very beginning of its life-cycle that can become a successful industrial district such as Silicon Valley of the present time or Cleveland, Ohio of the late nineteenth century. As evidenced by Lamoreaux, Levenstein, and Sokoloff (2004), such agglomerations can often be tracked down to one or two firms which acts as incubators for new firms with higher success probabilities. For simplicity, I assume that there is one such firm, which I call a hub firm and denote it by $h$. However, the analysis can be generalized to a case in which there are more than one hub firm. ${ }^{3}$ If this hub firm is unsuccessful, then, this is the end of the story. To model how success breeds success, the rest of the analysis, thus, focuses on a hub firm which is known to be a successful innovative firm.

There is also a unit mass of entrepreneurs who plan to engage in start-up activities in an innovative sector. ${ }^{4}$ It can be biotechnology or nanotechnology sectors today, and electric light, steel or chemistry sectors at the time of Brush Electric Company. Start-up activities require pre-establishment period preparations. These preparations can be anything related to the business project that entrepreneurs plan to employ in the post-establishment period. Innovative idea generation and business plans (such as marketing and pricing strategies) can summarize almost all of these pre-establishment period activities.

Entrepreneurs are in a position to decide over two options in phase I: becoming a standalone or a network entrepreneur. They can work on their projects alone in which case they have to come up with their innovative ideas independently and prepare their business strategies alone (call this as stand-alone entrepreneur). Alternatively, they can approach to the hub firm - where there may be other entrepreneurs working on similar projects - and try to make use of the collaborative environment in terms of innovative ideas and business plans by interacting with the other would-be entrepreneurs (call

\footnotetext{
${ }^{3}$ There is no harm to perceive the hub firm as a representative of all hub firms for my purpose in this paper, just like we do for "representative consumer" in consumption theory.

${ }^{4}$ Continuum of agents is assumed for technical convenience. The analysis can easily be modified to allow for discrete number of firms in which case one of the production factors should be infinitely indivisible to prevent technical complications
} 
this as network entrepreneur). Entrepreneur $i$ 's own effort creates a net benefit with a deterministic and a random part:

$$
b(e)+\varepsilon_{i} \quad \forall i \in[0,1],
$$

where $e$ is the level of effort and $b(e)$ is the deterministic part of the net benefit from effort with $b^{\prime}(e)>0$, and $\varepsilon_{i}$ is the individual specific random part of the net benefit from effort. This specification allows that some entrepreneurs may end up with better ideas even though all entrepreneurs are ex ante identical. A further specification of the random part is given at the end of this section.

In addition to the benefit that comes from effort, entrepreneurs also benefit by observing the other entrepreneurs around. This is simply the usual story of spillovers, but here they include not only technological knowledge but knowledge about business plans as well. I call them knowledge spillovers altogether and denote the amount of knowledge flows to an entrepreneur from another entrepreneur with $\beta$. As usual, how much entrepreneurs benefit from knowledge spillovers depends on their ability to value, exploit and apply the knowledge in their businesses. Denote absorptive capacity of an entrepreneur with $t$. Given a unit mass of entrepreneurs working on business projects in close proximity, the net benefit of an entrepreneur from knowledge spillovers is

$$
t \beta \quad \forall \beta \in[0,1] .
$$

Making use of (1) and (2), the total net benefit of becoming a stand-alone entrepreneur for entrepreneurs $i$ is

$$
V_{i}^{S}=b(e)+t \beta+\varepsilon_{i} \quad \forall i \in[0,1],
$$

where superscript $S$ denotes the set of stand-alone entrepreneurs.

The second option for an entrepreneur is to interact with the hub firm. Entrepreneurs who will potentially engage in start-up activities can benefit by interacting the established firms in the pre-establishment period for various reasons. The first and the most important channel is the role played by established firms as mediums of exchanging ideas. Lamoreaux, Levenstein, and Sokoloff (2004) reported how Brush Electric Company in Cleveland, Ohio fostered exchanging ideas to solve difficult problems and acted as a place for technological cross-fertilization in the era of Second Industrial Revolution. This exchange is, of course, not and should not be limited with innovative ideas. Firms of today do not have the luxury to learn how to sell innovative ideas by trial and error. For successful organizations, they have to develop marketable ideas that are backed up with strong business plans. For example, stable pricing and marketing strategies play crucial roles in determining the survival chances of start-up firms. Network entrepreneurs can learn or develop those techniques from other entrepreneurs in the network.

All of these create incentives for potential entrepreneurs to gather around established firms to exploit the knowledge exists in them. This may also be beneficial to the established firms since they can increase their stock of knowledge in this process of crossfertilization of ideas. All in all, we observe that some would-be entrepreneurs are part of a network in which one or two established firms are the crucial nodes. There are, of course, costs and benefits associated with being a member of this network for both parties. To highlight the results without unnecessary complications, this paper models the costs and benefits that accrue to the start-ups but takes the hub firm's decision 
as granted. Section 3.2 incorporates hub firm's decision and section 5 explores if there are incentives for hub firm to arrange this network. Moreover, there may be rationing in membership to this network. Presumably, established firms would not want to allow any number of entrepreneurs to join their networks. Not only because they might not have the resources for that but also because too many entrepreneurs interacting in the network may create congestion in exchanging ideas even when all entrepreneurs are identical.

When entrepreneurs join the network, they still need to provide the same effort in their pre-establishment period preparations. However, the benefit of being a part of the network allows them to benefit more from the knowledge of the network entrepreneurs. To capture these ideas, I assume that the knowledge spillover between network firms, denoted by $\alpha$, is greater than $\beta$. However, being a part of the network is costly. It is much like a club membership and all members have to pay a fee to enter the network, though the cost of entering this network need not to be pecuniary. It may well be the time and congestion costs associated with repeated interactions with other network members.

Let the ratio of entrepreneurs who choose to become a network entrepreneur be $\lambda$. Hence, the total net benefit of becoming a network entrepreneur for entrepreneur $i$ is

$$
V_{i}^{N}=b(e)+t[\lambda \alpha+(1-\lambda) \beta]-c+\varepsilon_{i} \quad \forall i, \alpha, \lambda \in[0,1] \wedge \alpha>\beta,
$$

where superscript $N$ denotes the set of network entrepreneurs and $c$ is the cost of entrering the network. This specification implies that knowledge may not spill over in the same extent within and outside the network which is consistent with Acs et al. (2005) that show that the spillover of knowledge may not occur automatically as has typically been assumed in endogenous growth models.

Some comments on the random part of the benefit from effort are in order. I assume that entrepreneurs - but no one else - learn $\varepsilon_{i}$ once they finalize their business plans but before they apply for business loans. I further assume that $\theta$ of the network entrepreneurs will have a good draw, $\varepsilon_{i}=\varepsilon_{H}>0$, and the rest will have a bad draw, $\varepsilon_{i}=\varepsilon_{L}<0$, such that $\varepsilon_{i}^{N}:=\mathbb{E}\left[\varepsilon_{i} \mid i \in N\right]=\theta \varepsilon_{H}+(1-\theta) \varepsilon_{L}$, where subscript $H$ is for high type and subscript $L$ is for low type. However, I assume that $\gamma$ of the stand-alone entrepreneurs will have a good draw and the rest will have a bad draw such that $\varepsilon_{i}^{S}:=\mathbb{E}\left[\varepsilon_{i} \mid i \in S\right]=$ $\gamma \varepsilon_{H}+(1-\gamma) \varepsilon_{L}$. Therefore, by the law of large numbers

$$
\operatorname{Pr}\left(\varepsilon_{i}=\varepsilon_{H}\right)=\left\{\begin{array}{ll}
\theta & \text { if } i \in N \\
\gamma & \text { if } i \in S
\end{array} \quad \forall i \in[0,1] \wedge \gamma<\theta \quad .\right.
$$

I assume that $\theta$ and $\gamma$ are common knowledge. ${ }^{5} \gamma<\theta$ is assumed to capture the network effect. It is well-known that successful networks have disproportionately more high-type individuals even though some stand-alone individuals can still achieve the same degree by themselves outside the network. ${ }^{6}$ Note that $\varepsilon_{i}^{N}>\varepsilon_{i}^{S}$. For future reference, define the difference between $\varepsilon_{i}^{N}$ and $\varepsilon_{i}^{S}$ as $\Delta \varepsilon$ for brevity of the equations. The analysis below

\footnotetext{
${ }^{5}$ This assumption is nothing but the conventional assumption in contract theory that the distribution of types are publicly known.

${ }^{6}$ Here is an analogy. A randomly selected researcher in the NBER network is more likely to be a better researcher, but this, by all means, does not mean that there cannot be other better researchers outside this academic alliance.
} 
focuses on the cases in which $c>\Delta \varepsilon .^{7}$

\subsection{Network formation}

I assume that the cost of joining the network is less than its net benefit, which is stated in the following assumption.

Assumption $1 t(\alpha-\beta)+\Delta \varepsilon>c$.

Given the specified net benefit scheme in the previous section, the network formation equilibrium is the ratio of entrepreneurs in the network, $\lambda^{*}$, such that none of the entrepreneurs have incentive to change their decisions on whether or not to join the network. At this phase, entrepreneurs do not yet have information about the random part of their net benefit from effort. Assuming that they are risk-neutral expected utility maximizers, in any equilibrium the following inequality must hold.

$$
\max \left\{\mathbb{E} V_{i}^{S}\left(\lambda^{*}\right), \mathbb{E} V_{i}^{N}\left(\lambda^{*}\right)\right\} \geq \max \left\{\mathbb{E} V_{i}^{S}(\lambda), \mathbb{E} V_{i}^{N}(\lambda)\right\} \quad \forall i, \lambda \in[0,1] .
$$

In an interior equilibrium, $\mathbb{E} V_{i}^{S}\left(\lambda^{*}\right)=\mathbb{E} V_{i}^{N}\left(\lambda^{*}\right)$ has to be satisfied. This implies that an interior equilibrium is obtained when

$$
\lambda^{*}=\frac{c-\Delta \varepsilon}{t(\alpha-\beta)}
$$

However, network externalities prevent this to be a stable equilibrium. Suppose the economy is in the interior equilibrium with $\lambda^{*}$ entrepreneurs in the network and the rest stands alone. If an entrepreneur decides to stand alone instead of joining the network, the expected net benefit of each of the other entrepreneurs in the network decreases by $t(\alpha-\beta)$ while the expected net benefit of stand-alone entrepreneurs remains unchanged. If, on the other hand, an entrepreneur does the opposite, the expected net benefit of each of other entrepreneurs in the network increases by $t(\alpha-\beta)$ while that of stand-alone entrepreneurs remains unchanged. Therefore, the interior solution $\lambda^{*}=(c-\Delta \varepsilon) /(t(\alpha-\beta))$ cannot be a stable equilibrium. Then, any stable equilibrium of network formation has to be a corner solution either with all entrepreneurs prefer to join the network $\left(\lambda^{*}=1\right)$ or none of them prefer to join the network $\left(\lambda^{*}=0\right)$.

Proposition 1 (Agglomeration vs. Dispersion) There are multiple equilibria of network formation and any stable equilibrium has to be a corner solution. Therefore, either all entrepreneurs agglomerate around the hub firm or all of them stands alone.

A graphical characterization of the equilibria is shown in Figure 1. The number of entrepreneurs forming links with the hub firm is given in the $x$-axis and entrepreneurs expected payoffs are given on the $y$-axis. $A B$ is the expected payoff of an entrepreneur when he joins the network. As expected, it is increasing in the number of entrepreneurs in the network. On the other hand, the payoff of an entrepreneur when he stands alone, which is represented by $C D$ in the figure, is independent of the number of entrepreneurs. Since joining the network is costly, $A B$ starts below $C D$.

\footnotetext{
${ }^{7}$ The case in which $c<\Delta \varepsilon$ is trivial and the analysis of it is left to the reader.
} 


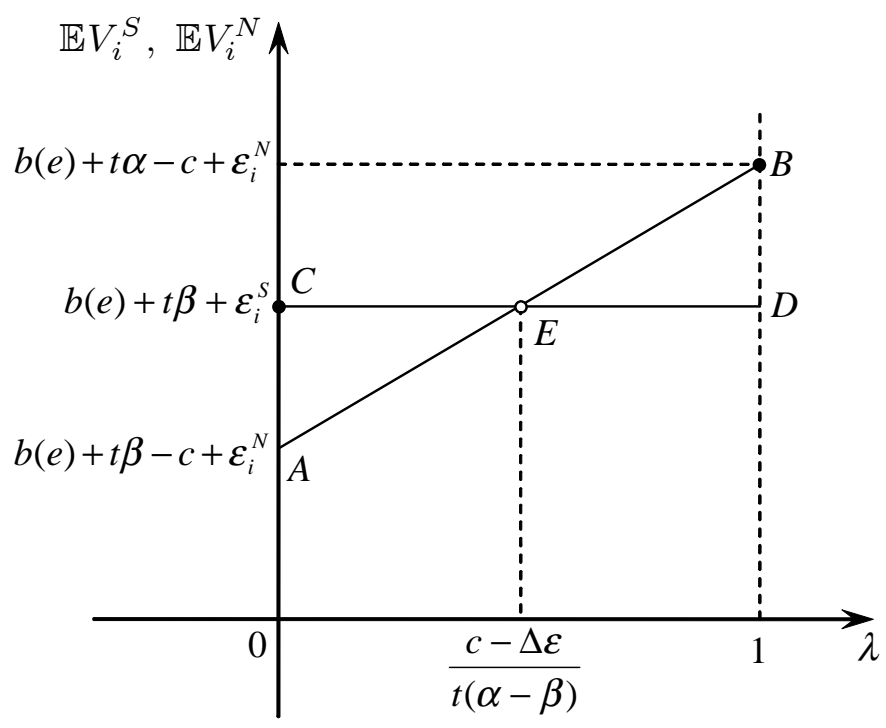

Figure 1: Network formation equilibria

There has to be sufficiently higher number of entrepreneurs in the network (e.g.; at least $(c-\Delta \varepsilon) /(t(\alpha-\beta))$ entrepreneurs) to make an entrepreneur at least as better of as he could be outside the network. Therefore, there is a coordination problem caused by network externalities: joining the network is individually rational only if enough others do so. As stated in Proposition 1, there are three different equilibria one of which is not stable. A stable equilibrium is obtained either when all entrepreneurs stand alone or all join the network. The former happens at point $C$ and the latter happens at point $D$ in the figure, both of which are corner solutions. An interior solution occurs where $A B$ intersects $C D$, which happens at point $E$. However, it is not stable since even a small perturbation or a shock to the system could lead the economy out of this equilibrium due to the snow ball effect.

\subsection{Network architecture: rationed agglomeration}

Previous section assumes an open-club-type of a network. Any entrepreneur who is willing to join the network can join. However, this neglects the decision of the hub firm. To incorporate that, assume for the moment that the economic problem of the hub firm prevents it from forming links with all firms and suppose that it is willing to create links only with $\eta$ of the entrepreneurs.

If $\eta<(c-\Delta \varepsilon) /(t(\alpha-\beta))$, then, there will be a complete dispersion of entrepreneurs. Such a situation is shown in Figure 2. Suppose the hub firm is willing to form links with $\eta_{1}$ entrepreneurs. Then, the equilibrium has to happen at point $C$ and it is the unique and stable equilibrium of network formation in this case. This is a case with low knowledge spillovers. Entrepreneurs cannot benefit much from the knowledge base of the network since the number of entrepreneurs allowed in the network is not sufficient for enough knowledge spillovers. In that sense, this is a bad equilibrium with no collaboration. An industrial district with these characteristics would probably experience lower growth rates. 


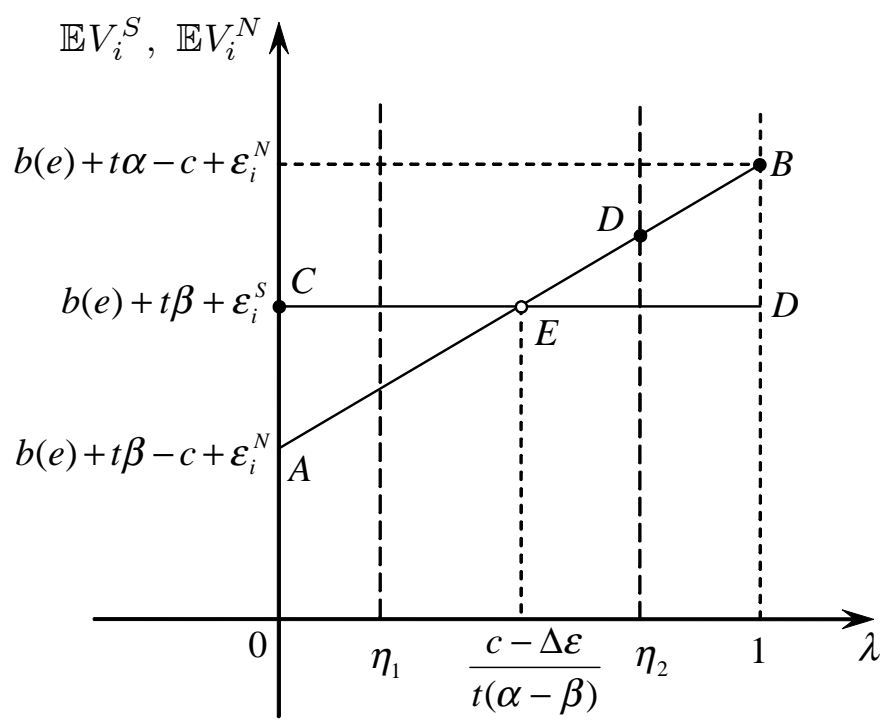

Figure 2: Hub firm's decision and network formation

If $\eta \geq(c-\Delta \varepsilon) /(t(\alpha-\beta))$, then $\eta$ entrepreneurs will be able to form links even though all entrepreneurs would prefer forming links with the hub firm. Figure 2 shows this situation. Suppose the hub firm is willing to form links with $\eta_{2}$ entrepreneurs. Then, a stable equilibrium occurs at point $D$. This means that $1-\eta_{2}$ entrepreneurs will not be able to join the network even though they want to. This suggests that there should be some kind of rationing by the hub firm in its selection process of entrepreneurs

Definition 1 (Rationed Agglomeration) A rationed agglomeration is an agglomeration of limited number of entrepreneurs around the hub firm(s) even though all entrepreneurs want to do so.

Under our assumption of identical entrepreneurs, the best the hub firm can do is a random rationing like in the models of credit rationing à la Stiglitz and Weiss (1981). Models of agglomeration usually predict either complete agglomeration or complete dispersion of entrepreneurs whenever there is a corner solution. Here, what I propose is somewhat different than those predictions and is more consistent with reality. What we observe in reality is some entrepreneurs that are related to each other and some others in the same sectors that stand alone. If agglomeration forces make forming links beneficial for an entrepreneur it has to do the same thing for all the others which are assumed to be identical in all respects. Nonetheless, even though agglomeration forces lead entrepreneurs to one or the other corner, some sort of rationing mechanism may prevent such outcomes. This makes ex ante identical entrepreneurs different ex post. Then, we end up with a corner solution which looks like an interior solution. ${ }^{8}$

Note that whenever $\eta \geq(c-\Delta \varepsilon) /(t(\alpha-\beta))$ in addition to the ones I analyze above, point $E$ would still be an equilibrium, but, as discussed before, it is unstable unless

\footnotetext{
${ }^{8}$ This can also be viewed as a gentlemen club or an academic alliance such as NBER. Even though many similar individuals prefer to be a part of them, there will be room only for a limited number of them. Then, the institution applies some rationing rule which may or may not be random.
} 
$\eta=(c-\Delta \varepsilon) /(t(\alpha-\beta))$ and is left aside in the analysis below. The results of this section are summarized in the following proposition.

Proposition 2 (Rationed Agglomeration) If $\eta<(c-\Delta \varepsilon) /(t(\alpha-\beta))$, there is complete dispersion of entrepreneurs. If $\eta \geq(c-\Delta \varepsilon) /(t(\alpha-\beta))$, only $\eta$ entrepreneurs can form links with the hub firm even though all of them prefer forming links. Then, there is agglomeration around the hub firm at the same time with some other entrepreneurs standing alone outside the network.

Finally, some comments on the multiplicity of equilibria are in order. The possibility of multiple equilibria explains why we observe different industrial architecture in different places and in different times. Whenever a dispersion equilibrium occurs (point $C$ in Figure 2), entrepreneurs do not collaborate with each other. In other equilibria (either unstable equilibrium of point $E$ or stable equilibrium of point $D$ ), there is high collaboration between entrepreneurs. Any unstable equilibrium will sooner or later be broken, which explains why some industrial clusters change their structure in very short period of time. These equilibria can also be ranked in terms of entrepreneurs' welfare. Points $C$ and $E$ give the same aggregate payoff to the entrepreneurs. However, at point $D$, network entrepreneurs get higher payoffs and stand-alone entrepreneurs get exactly the same payoffs that they would get in points $D$ and $E$. Therefore, the aggregate welfare of entrepreneurs is higher in point $D$ than points $C$ and $E$. In that sense, I conclude that $C$ and $E$ as inefficient equilibria by noting that this analysis neglects the payoff of the hub firm. ${ }^{9}$

The above analysis implicitly assumes a star network structure among the entrepreneurs. In a star network, one player (in this case the established firm) is at the center of the network and the others (in this case entrepreneurs) gather around it. This is not only a plausible network architecture that we observe in industrial clusters but also theoretically justifiable. Bala and Goyal (2000) work on very general payoff structures of noncooperative network formation games. They show that in a model of two-way knowledge spillovers, the strong Nash equilibrium of a network structure tend to be either an empty network in which none of the agents are connected to each other (coincides with the complete dispersion result of Proposition 2) or a star network (coincides with the agglomeration result of Proposition 2).

\section{Phase II: financing of business projects}

[...] before they would be willing to invest in new technological ventures, wealthy individuals had to be convinced of two things: first and most obviously, that it

\footnotetext{
${ }^{9}$ Nonetheless, note that to be able to get this result I do not even need a hub firm. Even in the absence of a hub firm, this result says that entrepreneurs might be better off by interacting with each other but they can end up with an inefficient equilibrium of no cooperation due to coordination problems. One might, therefore, be tempted to predict that entrepreneurs can cooperate by solving this coordination problem. Although it seems possible in this simple framework of identical entrepreneurs such an incentive vanishes in richer environments with heterogenous agents. The simple reason for this is that coordination might not make all entrepreneurs but only a subgroup of them better off in which case it is not supported by all (or possibly by the majority).
} 
was indeed possible to earn high rates of return by putting their money in this kind of enterprise; [...] by serving as the hub of overlapping networks of inventors and investors, [hub firms] could both stimulate ongoing inventive activity and provide the expertise needed to assess the economic merits of the resulting discoveries. (Lamoreaux, Levenstein, and Sokoloff, 2004, pg. 14)

In the second phase of the pre-establishment period of start-ups, entrepreneurs seek for finance for their risky investment projects. At this stage, they have already developed their business projects, established their network and finalized their business strategies. This means that they now know what kind of a project they have: a promising project with high success probability or a not so well project with a lower success probability.

The way I model this is the following. At the end of phase I, entrepreneurs learn random part of their net benefits from effort, which is denoted with $\varepsilon_{i}$ in eq. (1). Remember that the expected value of this random term is assumed to be zero no matter whether an entrepreneur is in the network or not. I assume that there is a one-to-one mapping from net benefits of the entrepreneurs to the success probability of their start-ups. Those who experiences a good draw, $\varepsilon_{H}$, will have a success probability of $p_{H}$, and those who experiences a bad draw, $\varepsilon_{L}$, will have a success probability of $p_{L}$ where $p_{H}>p_{L}$. That is,

$$
p_{i}=\left\{\begin{array}{cc}
p_{H} & \text { if } \varepsilon_{i}=\varepsilon_{H} \\
p_{L} & \text { if } \varepsilon_{i}=\varepsilon_{L}
\end{array} \quad \forall i \in[0,1]\right.
$$

The base model here thus boils down to a canonical project financing model with two types: entrepreneurs with high success probability projects and entrepreneurs with low success probability projects. However, there are two differences. First, entrepreneurs acquire their types from their interactions in phase I. Second, the distribution of project types differs according to the entrepreneurs' past decisions on whether to join the network or not. That is, $\theta$ of the network entrepreneurs have a high success probability project whereas only $\gamma$ of the stand-alone entrepreneurs have a high success probability project.

To focus on the interesting cases, from now on, I assume that $\eta \geq c /(t(\alpha-\beta))$, and thus, there are $\eta$ network entrepreneurs and $1-\eta$ stands-alone entrepreneurs. Given this, there are $\theta \eta$ entrepreneurs in the network whose projects have a high success probability and $(1-\theta) \eta$ entrepreneurs in the network whose projects have a low success probability. The corresponding numbers for the stand-alone entrepreneurs are $\gamma(1-\eta)$ and $(1-\gamma)(1-\eta)$, respectively. Therefore, the overall number of entrepreneurs with high success probability projects in the whole population is

$$
\theta \eta+\gamma(1-\eta)
$$

and that of entrepreneurs with low success probability projects is

$$
(1-\theta) \eta+(1-\gamma)(1-\eta)
$$

To be able to undertake the project a potential entrepreneur has to have $I$ units of capital. It is assumed for simplicity that all entrepreneurs have no wealth. Therefore, they need to borrow $I$ units of capital from a lender. In the base model, I assume that they finance their projects from one source which is consistent with the findings 
of Petersen and Rajan (1994) on small business financing. The cost of loanable funds is equal to the risk-free (gross) interest rate $R$ in the economy. If entrepreneurs are successful, the project yields $Y$ units of capital at the end of the period and if not it yields a small return, which is normalized to zero here. I also assume that all projects have a positive net present value which is stated in the following assumption.

\section{Assumption 2 (NPV of Projects) $p_{H} Y>p_{L} Y>R I$.}

Therefore, it is not only that all entrepreneurs prefer undertaking their projects had they could fully self-finance their projects by themselves but also that lenders prefer financing all projects. Therefore, the focus of this paper is not the inefficiencies rise up due to melons problem but simply the pricing problem of different projects and the resulting incentive scheme that induces certain network structure. ${ }^{10}$ As it is shown later, the start-ups of the entrepreneurs with high success probability projects are undervalued due to the cross-subsidization erected by pooling contracts in the credit market.

\subsection{Sequence of events}

The sequence of the events in phase II is as follows. Since every entrepreneur is assumed to have no wealth they all need to borrow to start their firms. At the beginning of the phase II, entrepreneurs sign financial contracts with lenders. Then, they make their investments. Successful entrepreneurs pay off their loans once their payoffs are realized.

\subsection{Lenders (banks and local financiers)}

There are risk neutral lenders in Bertrand competition with each other. They can be either banks or local financiers. They simultaneously form their beliefs and choose the contracts they will be offering taking the cost of loanable funds, which is equal to the risk-free interest rate of $R$, as given. At the moment, both banks and local financiers are assumed to have the same information set. However, later the analysis takes into account the possibility that local financiers can make use of local information that they can gather from their relationships with the hub firm. They offer contracts contingent on the announced type of an entrepreneur and the outcome (either success or failure) of their projects. Contracts specify the repayments to the lenders in both states of the world. Let the repayment to the lender be $D_{i}^{G}(R)$ in the good state and $D_{i}^{B}(R)$ in the bad state where $G$ is for good, and $B$ is for bad. The general form of the contract offered by lender $l$ is

$$
\boldsymbol{C}_{l} \equiv\left[\begin{array}{c}
C_{H} \\
C_{L}
\end{array}\right]=\left[\begin{array}{ll}
D_{H}^{G}(R) & D_{H}^{B}(R) \\
D_{L}^{G}(R) & D_{L}^{B}(R)
\end{array}\right]
$$

where $C_{H}$ is the contract designed for loan applicants with a high success probability project and $C_{L}$ is that for loan applicants with a low success probability project. I assume that there is limited liability, and, therefore, contracts cannot leave entrepreneurs with negative end-of-period payoffs:

$$
\pi_{i}^{G} \geq 0 \quad \text { and } \quad \pi_{i}^{B} \geq 0 \quad \forall i=H, L \quad,
$$

\footnotetext{
${ }^{10}$ Inci (2006) focuses on this inefficiencies by assuming that the low success probability start-ups have negative net present value. Note also that the problem here does not entail any credit rationing.
} 
where $\pi_{i}^{G}$ is the payoff of an entrepreneur in the good state and $\pi_{i}^{B}$ is the payoff of an entrepreneur in the bad state.

\subsection{Entrepreneurs}

The payoff of an entrepreneur, $\Pi$, is given by

$$
\Pi=p_{i}\left(Y-D_{i}^{k}(R)\right)-\left(1-p_{i}\right) D_{i}^{k}(R) \geq 0 \quad \forall i=H, L \quad \forall k=B, G .
$$

An entrepreneur is going to be successful with probability $p_{i}$ in which case he produces $Y$. He gives $D_{i}^{k}$ to the bank. Thus, the expected net return in case of a good state is $p_{i}\left(Y-D_{i}^{k}\right)$. If he is unsuccessful he produces something less than $Y$ (which is normalized to zero) and gives $D_{i}^{k}$ of it to the bank. However, limited liability prevents $D_{i}^{k}$ to be higher than what the entrepreneur has. Since the low output is normalized to zero $D_{i}^{k}$ is going to be zero as well but for the sake of generality of the analysis I keep it.

\subsection{Equilibrium definition}

I use the standard Bertrand-Nash equilibrium concept. An equilibrium is the contract offers by lenders that are consistent with each other. Each lender offers entrepreneurs a contract that maximizes their profits. Then, among all alternatives entrepreneurs choose the best contract for them. Formally, an equilibrium in the credit market is defined as follows.

Definition 2 (Equilibrium Concept) Assume that lenders are Bertrand-Nash players following pure strategies. Given $R$, a credit market equilibrium is the contract offers by lenders such that all contracts earn nonnegative profits and there are no new contracts that could earn higher profits.

An equilibrium has to be individually rational and incentive compatible for every entrepreneur. After normalizing the payoff of the entrepreneur in case of inactivity to zero, individual rationality asserts that an entrepreneur $i$ can earn at least as much as he could when he does not participate in the market at all:

$$
p_{i}\left(Y-D_{i}^{G}(R)\right)-\left(1-p_{i}\right) D_{i}^{B}(R) \geq 0 \quad \forall i=H, L \quad .
$$

Incentive compatibility assures that entrepreneur $i$ does not have incentive to apply for the loan contract aimed for entrepreneurs $j$ :

$$
p_{i}\left(Y-D_{i}^{G}(R)\right)-\left(1-p_{i}\right) D_{i}^{B}(R) \geq p_{i}\left(Y-D_{j}^{G}(R)\right)-\left(1-p_{i}\right) D_{j}^{B}(R) \quad \forall i, j=H, L \quad .
$$

Under these conditions, it is impossible to design contracts such that entrepreneurs with different projects in terms of success probabilities self select themselves into different contracts. Therefore, it is impossible to identify an entrepreneur with a high success probability project since it is always beneficial for an entrepreneur with a low success probability project to misrepresent himself as if he had a high success probability project. Lemma 1 proves this claim. 
Lemma 1 There exist no separating equilibrium in the credit market.

Proof. See Appendix A.1.

\subsection{Start-up financing without hub-signaling}

As a benchmark start of with the case in which there is a network but the hub firm has no role in start-up financing. In this case entrepreneurs simply apply for loans by themselves. From Lemma 1, it is known that the only possibility is a pooling contract which imposes $D_{H}^{G}(R)=D_{F}^{G}(R)=D^{G}$ and $D_{H}^{B}(R)=D_{L}^{B}(R)=D^{B}$. Figure 3 derives the pooling equilibrium. $Z P_{\bar{p}}$ is the zero profit condition with both types of projects above which the profit of the lender increases and under which it decreases. $Z P_{\bar{p}}$ is given by

$$
\bar{p} D^{G}+(1-\bar{p}) D^{B}=R I,
$$

where $\bar{p}$ is the average success probability of the projects of the loan applicant pool. The applicant pool is composed of both network and stand-alone entrepreneurs. By making use of (9) and (10), this average success probability can be written as

$$
\bar{p}=[\theta \eta+\gamma(1-\eta)] p_{H}+[(1-\theta) \eta+(1-\gamma)(1-\eta)] p_{L}
$$

To find out the pooling equilibrium, start of with an arbitrary contract, say, $C_{1}$. The iso-profit lines passing through $C_{1}$ are shown in Figure 3. The steeper one is for a low success probability project and the less steep one is for a high success probability project. $C_{1}$ cannot be an equilibrium since there is a deviation contract $C_{2}$ at the north-west of it which is attractive for an entrepreneur with a high success probability project but not for an entrepreneur with a low success probability project. There exist such deviation contracts as long as the contract is not on the $y$-axis. There is no such deviation contract on the $y$-axis since contracts have to be in the first quadrant due to limited liability. However, any contract there, such as $C_{3}$, cannot be an equilibrium as long as it makes positive profits since it can be under cut by Bertrand competition. Zero profits are obtained at the intersection of $Z P_{\bar{p}}$ and the $y$-axis which I denote with $C^{*}$. The pair of iso-profit lines passing through $C^{*}$ are shown with the lines $H H^{\prime}$ and $L L^{\prime}$ for a high and a low success probability project, respectively, in the figure.

The equilibrium pooling contract takes the simple debt form with a repayment of $R I / \bar{p}$ in the good state and zero repayment in the bad state:

$$
\begin{aligned}
D^{S} & =R I / \bar{p} \\
D^{F} & =0 .
\end{aligned}
$$

The effective interest rate on loans is $R / \bar{p}$.

\subsection{Local financiers and hub-signaling}

The entrepreneurs who organized and promoted [...] new ventures secured investment capital largely by relying on personal connections. [...] they could be based on 


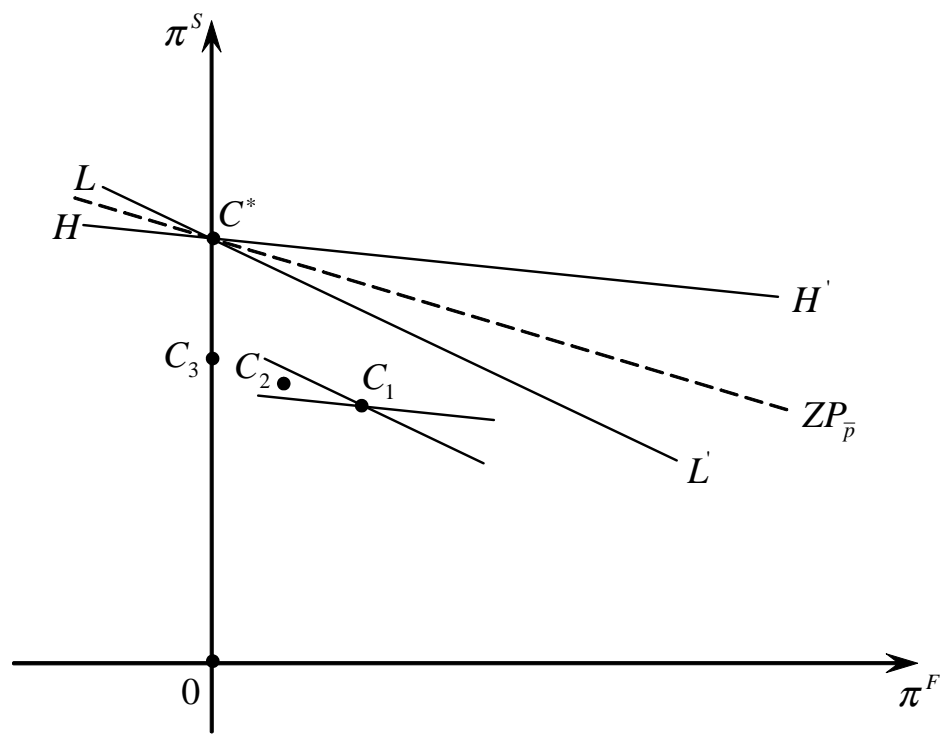

Figure 3: Pooling equilibrium without hub-signaling

the recommendations of men who had established their expertise in the community, as when Brush secured backing for the Linde Air Products Company simply by assuring local businessmen of the merits of the technology. (Lamoreaux, Levenstein, and Sokoloff, 2004, pg. 27)

Throughout phase I, entrepreneurs have had close and repeated relationships with the hub firm. The hub firm, thus, have a rough idea on the quality of the projects of these entrepreneurs. For the moment, I assume that this information is costless and comes naturally due to repeated interaction between the parties in phase I. Section 5.1 generalizes the model to a case in which gathering this information is costly.

The hub firm has close links with local financiers, too. These links can be due to ongoing or past financial relationships or it could be the case that these local financiers are organized by the hub firm or by its past employees as evidenced by Lamoreaux, Levenstein and Sokoloff (2004). It is known to be a successful firm that has been able to manage very successful business projects in the area.

Potential lenders have to be convinced that the projects they plan to finance are promising and they can trust the expertise of the hub firm in evaluating them. Therefore, local financiers can make use of the local information that the hub firm has, which a bank cannot credibly gather. Assume that the hub firm honestly communicates its ideas for the moment which allows me to focus on the value of network relationships in isolation. The credibility of this information is discussed in section 5.2.

Suppose the hub firm sends a signal $\sigma$ to the local financiers that takes on two values: good and bad. That is, it conveys its beliefs about every entrepreneur in the network by labeling them as good (an entrepreneur with a high success probability project) or bad (an entrepreneur with a low success probability project). It can, of course, make wrong judgments. The probability of a good signal for an entrepreneur with a high success 
probability project is

$$
\operatorname{Pr}\{\sigma=\operatorname{good} \mid i=H \wedge i \in N\}=x \quad x \in[0,1],
$$

and that for an entrepreneur with a low success probability project is

$$
\operatorname{Pr}\{\sigma=\operatorname{good} \mid i=L \wedge i \in N\}=y \quad y \in[0,1] .
$$

Then, conditional on a good signal from the hub firm, the Bayesian probability that a loan applicant is an entrepreneur with a high success probability project is

$$
\operatorname{Pr}\{i=H \mid \sigma=\operatorname{good} \wedge i \in N\}=\frac{\operatorname{Pr}\{i=H \wedge \sigma=\operatorname{good} \wedge i \in N\}}{\operatorname{Pr}\{\sigma=\operatorname{good} \wedge i \in N\}}=\frac{\theta x}{\theta x+(1-\theta) y}
$$

and conditional on a bad signal from the hub firm, the Bayesian probability that a loan applicant is an entrepreneur with a high success probability project is

$$
\operatorname{Pr}\{i=H \mid \sigma=b a d \wedge i \in N\}=\frac{\theta(1-x)}{\theta(1-x)+(1-\theta)(1-y)} .
$$

Similar expressions for the Bayesian probabilities that a loan applicant is an entrepreneur with a high and a low success probability project are given by

$$
\begin{aligned}
& \operatorname{Pr}\{i=L \mid \sigma=\text { good } \wedge i \in N\}=\frac{(1-\theta) y}{\theta x+(1-\theta) y} \\
& \operatorname{Pr}\{i=L \mid \sigma=b a d \wedge i \in N\}=\frac{(1-\theta)(1-y)}{\theta(1-x)+(1-\theta)(1-y)},
\end{aligned}
$$

respectively. Thus, the belief of the hub firm about the projects of the network entrepreneurs can be imperfect. That is, it can label a good project as a bad project with probability $1-x$ and a bad project as a good project with probability $y$. However, a firm that has engaged in many innovative activities and formulated successful business strategies, such as Brush Electric Company, would in average make valuable judgments about business projects. Given that it have had continuous relationship with the network entrepreneurs in phase I, thus, it is reasonable to assume that the hub firm's judgments about the network entrepreneurs are useful in average. Technically, this is achieved if monotone likelihood ratio property (MLRP) holds in the distribution of types. This requires the ratio the Bayesian probability of a good signal to a bad signal is increasing with the type of the projects. That is, the ratio $(21) /(22)$ should be greater than the ratio $(23 a) /(23 b)$ should hold, which boils down to the following assumption.

Assumption 3 (Informativeness of Signals) Signals are informative: $x>y$.

Suppose that these signals are received by at least two local financiers and they trust these signals. I assume that signals are private information between the hub firm and the local financiers and cannot be credibly communicated to anyone else. However, local financiers do know that the hub firm has contacts with other local financiers, too. These local financiers have some local information that none of the other lenders has.

In the case in which there is no hub-signaling, the average success probability of the loan applicant pool is given by $\bar{p}$ and, as is shown in (18a) and (18b), the equilibrium lending 
interest rate is $R / \bar{p}$ for any loan granted. However, the extra information that the local financiers have give them to ability to price discriminate between network entrepreneurs and stand-alone entrepreneurs. Suppose they grant the loans only if they get a good signal from the hub firm. The average success probability of network entrepreneurs with a good signal, $\hat{p}$, is

$$
\hat{p}=\frac{\theta x p_{H}+(1-\theta) y p_{L}}{\theta x+(1-\theta) y} .
$$

A similar analysis of section 4.5 with new (Bayesian) incentive constraints and (Bayesian) zero profit conditions shows that local financiers offer a lending interest rate of $R / \hat{p}$ to any network entrepreneur with a good signal. A simple comparison of (17) and (24) depicts that $\hat{p}>\bar{p}$ as long as $x>y$, which is assumed in Assumption 3. Therefore, the existence of a network allows local financiers to provide cheaper loans to network entrepreneurs with a good signal.

Those who were labeled with a bad signal are declined from the privileged loan provided by the local financiers. ${ }^{11}$ From the perspective of the local financiers, the average success probability of the loan applicants that are standing alone, $\check{p}$, is given by

$$
\check{p}=\frac{\gamma p_{H}+(1-\gamma) p_{L}}{\gamma+(1-\gamma)} .
$$

It is easy to show that $\check{p}<\bar{p}$. However, note that those who could not get a privileged loan from the local financiers can apply for loans as stand-alone firms. This changes the average success probability of the stand-alone loan applicants. Having known this, banks and local financiers set the price of the loans accordingly. The new average success probability outside the network is now given by

$$
\tilde{p}=\frac{[(1-x) \theta \eta+\gamma(1-\eta)] p_{H}+[(1-y)(1-\theta) \eta+(1-\gamma)(1-\eta)] p_{L}}{[(1-x) \theta \eta+\gamma(1-\eta)]+[(1-y)(1-\theta) \eta+(1-\gamma)(1-\eta)]} .
$$

It is also easy to show that $\tilde{p}<\bar{p}$. The reason for this is the following. The average success probability of the whole population is $\bar{p}$. A sample of this population, which has an average success probability of $\hat{p}>\bar{p}$, is in the network. Therefore, the average success probability of the remaining population has to be less than $\bar{p}$.

Suppose this static game is played at every period. Then, the network of the hub firm - which is known to be a successful firm - incubates start-ups with better chances of survival in average than the rest of the start-ups. This means a better match of capital to ideas in the network. I record this result in the following proposition. That is, networks successful firms give births to successful firms.

Proposition 3 Success breeds success in the network.

Figure 4 shows the affect of hub-signaling in and of itself in the credit market. In the absence of hub-signaling all lenders offer one pooling contract for all borrowers. In this case, the zero profit condition is given by $Z P_{\bar{p}}$ and the equilibrium contract is

\footnotetext{
${ }^{11}$ Here is an analogy. NBER grants some professors as "faculty research fellows". Some of these are not tenured even though they have strong research records.
} 


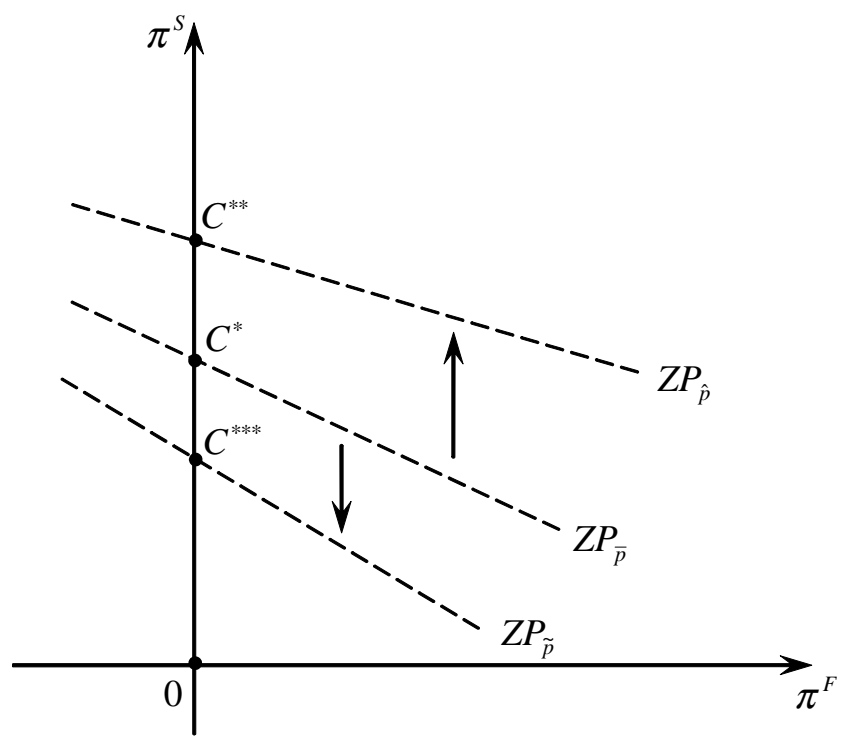

Figure 4: Equilibrium contracts with and without hub-signalling

characterized by $C^{*}$, which is the same $C^{*}$ shown in Figure 3 . When there is hubsignaling, the local financiers can effectively price discriminate between the two groups of borrowers. The first group is composed of network entrepreneurs that are labeled with a good signal by the hub firm. Given the information structure, local financiers have informational advantage about the quality of these firms. The zero profit condition is given by $Z P_{\hat{p}}$ for the loans they provide to the entrepreneurs with good signals. The equilibrium contract for this group is given by $C^{* *}$. Note that this contract gives higher payoffs to the entrepreneurs in case of a good state at the end of the period. The second group is composed of two different kinds of entrepreneurs: stand-alone entrepreneurs and network entrepreneurs who are labeled with a bad signal by the hub firm, and thus, declined from the privileged loans provided by the local financiers. The average success probability in this group is $\tilde{p}$ and the zero profit condition is given by $Z P_{\tilde{p}}$ for the banks. The corresponding equilibrium contract is given by $C^{* * *}$. Note that $C^{* * *}$ leaves a smaller payoff to the entrepreneurs in the good state. Table 1 summarizes the lending interest rates offered by lenders.

\begin{tabular}{|c|c|c|c|}
\hline & \multicolumn{2}{|c|}{ Lending Interest Rate } \\
\hline & & $\begin{array}{l}\text { for stand-alone } \\
\text { entrepreneurs }\end{array}$ & $\begin{array}{l}\text { for network } \\
\text { entrepreneurs }\end{array}$ \\
\hline \multirow{2}{*}{$\begin{array}{c}\text { without } \\
\text { hub-signaling }\end{array}$} & Banks & $R / \bar{p}$ & $R / \bar{p}$ \\
\hline & Local Financiers & $R / \bar{p}$ & $R / \bar{p}$ \\
\hline \multirow{2}{*}{$\begin{array}{c}\text { with } \\
\text { hub-signaling }\end{array}$} & Banks & $R / \tilde{p}$ & $R / \tilde{p}$ \\
\hline & Local Financiers & $R / \tilde{p}$ & $R / \hat{p}$ \\
\hline
\end{tabular}

Table 1: Lending interest rates

The results would still go through even when the entrepreneurs are risk averse. In section 5, I show that the existence of a network makes either both high and low success probability entrepreneurs better off or only the high success probability entrepreneurs. 
Being a part of the network is preferable by both parties in the former case. In the latter case, low success probability entrepreneurs do not want to be a part of the network but doing so would perfectly signal their types. Therefore, they would not leave the network after learning their types. Instead they might want to give side payments to the hub firm to collapse the informative signaling mechanism. As is shown in section 5 , even with this side payments a network would still persist. This suggests that the qualitative results are robust even with risk averse agents noting that all entrepreneurs have freedom to leave the network any time they want.

The results imply that the average success probability of start-ups that are financed by the privileged loans of the local financiers are going to be more successful in average. However, this does not mean that the region benefits from it. As the model shows, entrepreneurs rationed from the privileged loan can apply for loans as stand-alone entrepreneurs. In the end, although some of the entrepreneurs will be paying lower prices for the loans, all firms will have access to credit and the distribution of types will be the same with the case in which there is no hub-signaling. The only benefit of the network to the society is thus the fact that it is an incubator of relatively more high success probability firms (that is $\theta>\gamma$ ), which happens in phase I. In phase II, the network creates an island of entrepreneurs that have access to cheaper loans and they are high success probability firms in average.

One important point to note is that the performance of the economy is dependent on the informativeness of the signals. Arnott and Stiglitz (1991) show that a nonmarket institution (network of entrepreneurs in this paper) may be dysfunctional in the cases in which it is informationally disadvantaged relative to the market institution. In this paper, I assume that the signals are informative, but, from a social point of view, the outcome of the economy is not any better than the equilibrium without a hub-signaling mechanism. Therefore, nonmarket institutions may not only be dysfunctional when they are informationally disadvantaged as in Arnott and Stiglitz (1991) but they may also be useless for the goals of the society even though they have superior information about the economy. The benefits of the nonmarket institution accrue only to its privileged members in terms of prices of the loans, but those who can enter into entrepreneurship are still the same. However, this does not mean that the networks are completely useless simply because networks can create more high success probability projects in phase I.

\subsection{Monopolistic local financier}

An important thing to note is that the price of the loan that is offered to the network entrepreneurs does not necessarily decrease due to hub-signaling. This result is dependent on the credit market specification. I assumed that the lenders are in a Bertrand competition. In general lenders (in particular local financiers) may have monopolistic power which might prevent prices to go down. To see that, suppose for the moment an extreme case in which there is only one local financier that has access to the signals of the hub firm. The extra information it has effectively improves its expected nonrepayed loans such that if it were to compete with others, its zero profit condition would be characterized by $Z P_{\hat{p}}$ in Figure 4 . However, the monopolistic local financier does not need to pass on this cost decrease to the loan applicants. It cannot achieve the complete monopoly profits either since other lenders are offering $R / \bar{p}$. This is simply because network entrepreneurs would apply for loans as stand-alone firms if the price of the loan 
is higher than $R / \bar{p}$. Therefore, a monopolistic local financiers sets the same loan price that all others are currently offering in the market and enjoy profits of $R(1 / \bar{p}-1 / \hat{p})$ per dollar lent. In general, the outcome depends on how informed the lenders are.

Petersen and Rajan (1994) assume that the decreases in cost of loanable funds are passed on to the borrowers. In this model, cost of loanable funds - which is nothing but the risk-free interest rate $R$ - does not change. However, the monopolistic local financier expects to have a lower number of defaults. This effectively decreases its expected losses, but it does not need to reflect this chance to the borrowers since it has monopoly power.

Note that, this has nothing to do with the fact that success breeds success in the network. Even though the price of the loans does not go down in the case of a monopolistic local financier, there is still a better match of capital with the ideas among those who are financed by the privileged loan of the local financier. That is, the average success probability in the network is higher than that outside the network. ${ }^{12}$

\section{Incentives for hub-signaling}

Until now, I had assumed that there are certain incentives to the hub firm to form the signaling mechanism. Here, I analyze these incentives for such an organization. From an ex ante point of view, in the absence of hub-signaling, the market value of any start-up firm, $\overline{\mathcal{V}}$, is given by

$$
\overline{\mathcal{V}}=\bar{p} Y-R I,
$$

regardless of whether the entrepreneur has a high or a low success probability project. As it should be clear by now, credit markets undervalue the start-ups of entrepreneurs with high success probability projects at the same time that they overvalue the startups of entrepreneurs with low success probability projects. However, the hub-signaling mechanism changes the levels of under- and overvaluation of start-ups. When there is hub-signaling, the market value of the start-up of a network entrepreneur with a high success probability project, $\mathcal{V}_{H}$, is

$$
\mathcal{V}_{H}=[x \hat{p}+(1-x) \tilde{p}] Y-R I
$$

and that of a network entrepreneur with a low success probability project, $\mathcal{V}_{L}$, is

$$
\mathcal{V}_{L}=[y \hat{p}+(1-y) \tilde{p}] Y-R I
$$

The following proposition proves that network entrepreneurs with high success probability project always projects prefer hub-signaling, but the decision of the network entrepreneurs with low success probability projects depends on the network size, number of high success probability projects in the network, and the informativeness of the signals.

Proposition 4 A network entrepreneur with a high success probability project always prefer hub-signaling. A network entrepreneur with a low success probability projects

\footnotetext{
${ }^{12}$ Outside of the network includes stand-alone entrepreneurs and network entrepreneurs who are labeled with a bad signal. The second group is considered to be outside the network since they independently apply for loans.
} 
prefer hub-signaling when the network is large enough (given the signal structure $\eta>$ $\left.\frac{y}{\theta x+(1-\theta) y}\right)$ or alternatively signals are not sufficiently informative (given the network size $\left.\frac{x}{y}>\frac{1-(1-\theta) \eta}{\theta \eta}\right)$. Otherwise, they prefer status-quo.

\section{Proof. See Appendix A.2.}

This suggests that, given the size of the network, hub-signaling makes the network entrepreneurs with low success probability projects better off only if the signals are not so informative or, given the signal structure, it makes them better off only if the network is large enough. The reason for this result is the cross-subsidization induced by contractual structure in the credit market. The start-ups of the network entrepreneurs with low success probability projects are overvalued due to pooling contracts, and this results in a wealth distribution from the owners of the undervalued start-ups to the owners of the overvalued start-ups. Therefore, the pricing of the projects are not the first-best. Hub-signaling can improve the situation by mitigating the adverse selection problem for some network entrepreneurs.

Ex ante, owners of the high success probability projects faces the chance of getting a good signal with probability $x$ at the same time that they face the possibility of a bad signal in which case their project is going to be even more undervalued. However, it turns out that the as long as signals are informative, the former effect dominates the latter. The situation is different for the network entrepreneurs with low success probability projects. They always want to misrepresent themselves as if they had high success probability projects. Given a network of a fixed size, they still have a chance to get a good signal if the signals are not very informative. This increases the level of overvaluation to even higher values. However, if the signals are sufficiently informative, they are more likely to be caught by the hub-signaling mechanism in which case they have to get loans with an interest rate of $R / \tilde{p}$. From another perspective, given the signal structure of the hub firm, if the network is large enough, they still have a high chance of not being caught by the signaling mechanism which might make them better off in expected terms. Therefore, in smaller networks with effective signaling structure, network entrepreneurs with low success probability projects are most likely to be worse off whereas in bigger networks with cumbersome signaling structures they might be better off.

Corollary 1 When the network is sufficiently large (e.g.; $\left.\eta>\frac{y}{\theta x+(1-\theta) y}\right)$, both high and low success probability project owners prefer hub-signaling.

Proof. The result directly follows from Proposition 4.

Focus now on to the more interesting case in which the network is sufficiently small (e.g.; $\left.\eta<\frac{y}{\theta x+(1-\theta) y}\right)$. A network entrepreneur with a high success probability project is willing to make a side payment to the hub firm to induce it to organize the hub-signaling mechanism. This side payment can at most be $\mathcal{V}_{H}-\overline{\mathcal{V}}$. On the other hand, a network entrepreneur with a low success probability project is willing to give a side payment to the hub firm to prevent it from organizing the hub-signaling mechanism. This side payment can at most be $\overline{\mathcal{V}}-\mathcal{V}_{L}$.

Whether the hub firm organizes the hub-signaling mechanism depends on the size of the total side payments by both groups of entrepreneurs. As opposed to Campbell and 
Kracaw (1980), which states that there would be no incentives for signaling in such situations, I show here that there can be a rational expectations equilibrium in which there are incentives to form hub-signaling. The basic intuition for the nonexistence of rational expectations equilibrium in Campbell and Kracaw (1980) is that, since banks make zero profits, the overvaluation of the firms should exactly match with the undervaluation of firms in equilibrium. In our setting this corresponds to the following equalities.

$$
\begin{aligned}
{[(1-x) \eta \theta+\gamma(1-\eta)]\left(p_{H}-\tilde{p}\right) } & =[(1-y) \eta(1-\theta)+(1-\gamma)(1-\eta)]\left(\tilde{p}-p_{L}\right)(30 \mathrm{a}) \\
x \theta\left(p_{H}-\hat{p}\right) & =y(1-\theta)\left(\hat{p}-p_{L}\right) .
\end{aligned}
$$

The first one focuses on the cross-subsidization between entrepreneurs with high and low success probability projects that are either stand-alone entrepreneurs or network entrepreneurs who are rationed from privileged loans. The second one focuses on the cross-subsidization among the network entrepreneurs who finances their start-ups with the privileged loans. However, these are ex post realizations. From an ex ante point of view, the total amount of overvaluation and undervaluation between network entrepreneurs are not equal to each other, which suggest that they may be a rational expectation equilibrium. The following proposition formally proves this claim.

Proposition 5 Suppose the network is sufficiently small (e.g.; $\eta<\frac{y}{\theta x+(1-\theta) y}$ ). The total increase in the market value of the start-ups of network entrepreneurs with high success probability projects due to hub-signaling is higher than the total decrease in the market value of the start-ups of the network entrepreneurs with low success probability projects.

\section{Proof. See Appendix A.3.}

In Proposition 4, when the network is sufficiently small, I showed that any network entrepreneur with a high success probability project is willing to offer a side payment to the hub firm to induce it to arrange hub-signaling and any network entrepreneur with a low success probability project owner is willing to offer a side payment to the hub firm to prevent it from arranging hub-signaling. Proposition 5 shows that the total amount of side payments by the network entrepreneurs with high success probability. Moreover, in Corollary 1, I show that both parties prefer hub-signaling if the network is sufficiently large. Therefore, there may be incentives to form the hub-signaling mechanism, which is stated in the following corollary.

Corollary 2 There may be incentives for the hub firm to arrange hub-signaling mechanism.

Proof. The result directly follows from Proposition 4, Corollary 1, and Proposition 5.

\subsection{Costly signaling and the price of a signal}

In the previous sections, I assume that the information required for signals is a natural by-product of the close and repeated interaction between the hub firm and the network 
entrepreneurs. This is partly realistic because social relationships occasionally bring useful information. In general, extracting this information can be costly to the hub firm although it comes naturally from its interaction with the network entrepreneurs. This section, which is based on Campbell and Kracaw (1980), sketches the more general case in which the cost of information extraction is $C$ per network entrepreneur.

Let the side payment that a network entrepreneur with an undervalued project is willing to offer to the hub firm to induce hub-signaling be $S_{H}$. This side payment can at most be equal to the total amount of market value change in the start-up of the network entrepreneur $\left(S_{H}<\mathcal{V}_{H}-\overline{\mathcal{V}}\right)$. Moreover, it has to cover the cost of information extraction $\left(S_{H}>C\right)$. Therefore, if all network entrepreneurs with undervalued start-ups in the network offer side payments to the hub firm, $\eta \theta C<\eta \theta S_{H}<\eta \theta\left(\mathcal{V}_{H}-\overline{\mathcal{V}}\right)$ has to hold, or simply

$$
C<S_{H}<\mathcal{V}_{H}-\overline{\mathcal{V}}
$$

In the same way, let the side payment that a network entrepreneur with an overvalued project is willing to pay be $S_{L}$. This side payment can at most be $\overline{\mathcal{V}}-\mathcal{V}_{L}$, and since not producing the signal is costless it should also be higher than zero. Therefore, if all network entrepreneurs with overvalued start-ups in the network offer side payments, $0<\eta(1-\theta) S_{L}<\eta(1-\theta)\left(\overline{\mathcal{V}}-\mathcal{V}_{L}\right)$ has to hold, or simply

$$
0<S_{L}<\overline{\mathcal{V}}-\mathcal{V}_{L}
$$

In the previous section, I show that the total amount of side payments by the network entrepreneurs with undervalued projects is higher than that by the network entrepreneurs with overvalued projects. Therefore, if

$$
\theta\left(\mathcal{V}_{H}-\overline{\mathcal{V}}\right)-C>(1-\theta)\left(\overline{\mathcal{V}}-\mathcal{V}_{L}\right)
$$

or simply,

$$
C<\theta \mathcal{V}_{H}+(1-\theta) \mathcal{V}_{L}-\overline{\mathcal{V}}
$$

there can be incentives to form hub-signaling mechanism. This means that if the cost of acquiring information is small enough, which is most likely to be the case for an experienced hub firm such as Brush Electric Company, there will be hub-signaling.

Proposition 6 There exists a level of side payments such that the hub firm invests in signal extraction.

\subsection{Reliability of signals}

Some of the men who invested their savings in the new firms were also officers and directors of banks. For example, James J. Tracy, one of the original incorporators of Brush Electric, became vice president of the Society for Savings after a long career in various other Cleveland financial institutions. Similarly, Myron T. Herrick, a member of the Sperry Syndicate and one of the initial investors in National Carbon, was secretary-treasurer and then president of the Society for Savings, a founder of the Euclid Avenue National Bank, a director of the American Exchange National Bank, and a director of the Garfield Savings Bank. Some of the inventors and 
other businessmen involved in these startups and spinoffs also helped to organize financial institutions during this period [...]. (Lamoreaux, Levenstein, and Sokoloff, 2004, pg.29)

The implicit assumption in the above analysis is that the hub firm honestly conveys the information it has to the local financiers. In reality, the credibility of the signals is questionable. One way of overcoming this problem for the local financiers is to finance the entrepreneurs in which the hub firm is also a claimant. That is, if the hub firm claims the entrepreneurs it labels as good have higher average success probabilities in average, then it should also be willing to invest in them. From the other way around, the signals should be credible if the hub firm holds a sufficient amount of equity in the portfolio of start-ups it labels with good signals.

Suppose, the hub firm has $\eta(\theta x+(1-\theta) y) W$ units of capital that it can allocate for investment in start-ups of the network entrepreneurs. I assume that this wealth is observable by local financiers and $W<I$. I also assume that the local financiers can verify whether the hub firm really invested in the start-ups of the network entrepreneurs. There are $\eta(\theta x+(1-\theta) y)$ network entrepreneurs that the hub firm labels with a good signal. An optimal investment strategy for the hub firm is to invest an equal share of its wealth endowment into these start-ups, which means that it invests $W$ units of capital in each start-up in its portfolio to get $\alpha<1$ share of each of them. ${ }^{13}$ If it honestly produces the signals, its payoff is

$$
\eta(\theta x+(1-\theta) y)[\alpha \hat{p}(Y-R(I-W))-R W]-\eta C \quad .
$$

The first term is the net return on the investment. It gets $\alpha$ share of each start-up by paying $W$ for each. There are $\eta(\theta x+(1-\theta) y)$ such entrepreneurs and their average success probability is $\hat{p}$. Those entrepreneurs need only $I-W$ units of capital from local financiers to start their firms. The second term is the cost of extracting information for the hub firm.

Alternatively, the hub firm can choose $\eta[\theta x+(1-\theta) y]$ firms randomly without incurring the cost of extracting information and announces them as the ones with good signals to the local financiers. If it does that, the average success probability in this random sample is going to be

$$
\breve{p}=\theta p_{H}+(1-\theta) p_{L},
$$

where $\breve{p}<\hat{p}$. This time, the payoff of the hub firm is

$$
\eta(\theta x+(1-\theta) y)[\alpha \breve{p}(Y-R(I-W))-R W] .
$$

A simple comparison of (35) and (37) shows that, given $W$, honestly reporting signals is preferable by the hub firm if it buys sufficiently large share of each start-up

$$
\alpha>\frac{C}{(\theta x+(1-\theta) y)(Y-R(I-W))(\hat{p}-\breve{p})} .
$$

This suggests not only that the signals of the hub firm is reliable if it invests in the

\footnotetext{
${ }^{13}$ Note that debt is the optimal way of financing in this model. However, here, there is a hub firm which decides first to buy an $\alpha$ share of the potential start-up, and then, the owner of this potential start-up looks for financing for the remaining part of the start-up. So, equity financing here can be seen as a device used by the hub firm to credibly send the signals to the local financiers.
} 
portfolio of the start-ups for which it sends signals to the local financiers but also a hub firm has to have a deep pocket to credibly engage in hub-signaling. Some of the results of this section are recorded in the following proposition.

Proposition 7 The signals of the hub firm is reliable if it buys a sufficiently large shares of the portfolio of start-ups for which it sends signals to local financiers.

\section{Conclusion}

In this paper, I offer some thoughts on how success breeds success locally. I model the pre-establishment period of start-ups. It is shown that a networking structure leads potential entrepreneurs and hub firms to form what I call a rationed agglomeration in which there are both entrepreneurs who interact with each other within the network and other entrepreneurs in the same business outside the network. I also show that established firms can help network entrepreneurs in obtaining financing for their startups. Although this help may improve the match of capital to ideas for some privileged members of the network, the overall distribution of capital to ideas remain unchanged. Therefore, the only benefit of the networks to the society at large comes in phase I of the pre-establishment period - the period in which entrepreneurs develop innovative ideas and work on business plans. That is, the networks can act as places for cross-fertilization of ideas by generating a disproportionately high number of superior ideas.

It is clear that entrepreneurs have an incentive to join the network of a hub firm, but some of them cannot do so because of the rationing by the hub firm. However, explaining why a hub firm forms such a network is not entirely trivial. In the presence of asymmetric information between the entrepreneurs and financiers, the market overvalues the start-ups with low success probabilities and undervalues the start-ups with high success probabilities. When the hub firm shares its information about the entrepreneurs in its network with the local financiers, the level of under- and overvaluation is altered for the network entrepreneurs. This sometimes makes both parties better off, and sometimes makes only the start-ups with high success probabilities better off. In the former case, when both parties are able to provide side payments to the hub firm, it is obvious that there are incentives for the hub firm to communicate its views to the local financiers.

It turns out that the hub firm also has incentives in the latter case, in which only the start-ups with high success probabilities are benefited so that the interests of the two parties are conflicting. This is simply because the side payments that the start-ups with the high success probabilities are willing and able to offer to the hub firm to induce it to communicate its ideas to the local financiers are greater in amount than the side payments that the start-ups with low success probabilities are willing and able to pay to the hub firm to induce it not to do so. This suggests that there are always certain incentives for the hub firm to decrease the information gap between the entrepreneurs and the local financiers. One potential problem in this is that the hub firm might not share its views honestly with the local financiers if collecting this information is costly. Nonetheless, the reliability of the signals is guaranteed whenever the hub firm buys sufficiently large shares of the portfolios of start-ups in its network that it claims to be promising, which is consistent with what is observed in the early stages of industrial districts. 
I explain how the information generated in the networks of entrepreneurs around established firms and start-ups can mitigate the adverse selection problems for some privileged members of the network by decreasing the information gap between the network entrepreneurs and local financiers. This is one explanation why we observe successful agglomerations such as those found in Cleveland, Ohio in the ninetieth century. It remains unexplained, however, why some agglomerations rise up repeatedly while others rise and decline.

While writing this paper, I came across the Green Paper: Entrepreneurship in Europe (European Commission, 2003) which stresses that networks between established firms and start-ups have been becoming increasingly important. Having understood the vitality of such networks in 1997 the Federal Ministry of Education and Research in Germany launched a program called EXIST to increase regional cooperation between the economic and scientific actors by forming networks between them. Two of the aims of the program are to increase knowledge spillovers and foster the pool of potential entrepreneurs by creating networks that would otherwise not formed. This suggests the feasibility of the idea that the government might improve the structures of the networks. The normative conclusions and public policies are left for future research.

\section{A Appendix}

\section{A.1 Proof of Lemma 1}

Assume instead there is a separating equilibrium. The Bertrand competition among the lenders requires that they make zero profits in an equilibrium. Therefore, if there were separating contracts, lenders have to make zero profits from each of these contracts. The zero profit condition for the contract designed for entrepreneurs with a high success probability projects is given by

$$
p_{H}\left(Y-\pi_{H}^{G}\right)-\left(1-p_{H}\right) \pi_{H}^{B}=R I,
$$

and that for an entrepreneur with a low success probability project is given by

$$
p_{L}\left(Y-\pi_{L}^{G}\right)-\left(1-p_{L}\right) \pi_{L}^{B}=R I .
$$

The corresponding iso-profit lines are given by

$$
\begin{aligned}
p_{H} \pi_{H}^{G}+\left(1-p_{H}\right) \pi_{H}^{B} & =\bar{Y}_{H} \\
p_{L} \pi_{L}^{G}+\left(1-p_{L}\right) \pi_{L}^{B} & =\bar{Y}_{L},
\end{aligned}
$$

where $\bar{Y}_{H}$ and $\bar{Y}_{L}$ are the levels of $Y_{H}$ and $Y_{L}$. If there were a pooling contract eqs. (A-1)-(A-3b) have to be satisfied simultaneously. However, note that (A-1) is parallel to (A-3a) and (A-2) is parallel to (A-3b) in the $\pi^{B}-\pi^{G}$ space, and the slope of the former group is smaller than that of the latter group. Given limited liability, these four equations cannot be satisfied at the same time with a separating contract. A contradiction is obtained. Therefore, there are no separating contracts.

\section{A.2 Proof of Proposition 4}

If the difference between $\mathcal{V}_{H}$ and $\overline{\mathcal{V}}$ is positive, the market value of the start-up of a network entrepreneur with a high success probability project increases due to hub-signaling. That is, 
$\mathcal{V}_{H}-\overline{\mathcal{V}}=[x \hat{p}+(1-x) \tilde{p}] Y-\bar{p} Y>0$. This holds when

$$
x \hat{p}+(1-x) \tilde{p}>\bar{p}
$$

By substituting for $\tilde{p}, \bar{p}$, and $\hat{p}$, one can get

$$
\frac{\left(p_{H}-p_{L}\right)(x-\theta \eta x-(1-\theta) \eta y)[\theta x-(\theta x+y(1-\theta))(\eta \theta+\gamma(1-\eta))]}{[\theta x+(1-\theta) y][1-(\theta \eta x+\eta y(1-\theta))]}>0 \quad .
$$

It can be easily verified that the terms $\left(p_{H}-p_{L}\right)$ and $[\theta x+(1-\theta) y]$ are positive. Then, $(\mathrm{A}-4)$ holds when

$$
\frac{(x-\eta[\theta x+(1-\theta) y])[\theta x-(\theta x+y(1-\theta))(\eta \theta+\gamma(1-\eta))]}{1-\eta(\theta x+y(1-\theta))}>0
$$

The first term in the numerator is positive because $\theta x+(1-\theta) y$ is a weighted average of $x$ and $y$, and therefore, it is between $x$ and $y$. Multiplying this with $\eta$, one get a number between $\eta x$ and $\eta y$, which is definitely less than $x$. Moreover, by similar reasoning, the term in the denominator is also positive since $\eta(\theta x+y(1-\theta))$ is less than one.

Below is the second term in the numerator.

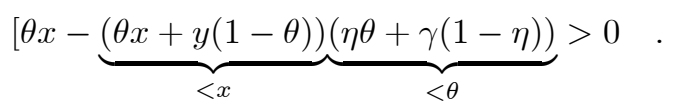

As it is obvious, $\eta \theta+\gamma(1-\eta)$ is in between $\theta$ and $\gamma$, and thus, it is less than $\theta$. Above I have already shown that $\theta x+y(1-\theta)<x$. Then, the second term in $(\mathrm{A}-5)$ has to be less than $\theta x$, which implies that the term is positive. Therefore, hub-signaling makes the network entrepreneurs with a high success probability projects better off.

Similarly, if the difference between $\overline{\mathcal{V}}$ and $\mathcal{V}_{L}$ is positive, the market value of the start-up of a network entrepreneur with a low success probability decreases due to hub-signaling. That is, $\overline{\mathcal{V}}-\mathcal{V}_{L}=\bar{p} Y-[y \hat{p}+(1-y) \tilde{p}] Y>0$. This holds when

$$
y \hat{p}+(1-y) \tilde{p}<\bar{p}
$$

By substituting for $\tilde{p}, \bar{p}$, and $\hat{p}$, one can get

$$
\frac{\left.\left(p_{H}-p_{L}\right)[y-\theta \eta x-(1-\theta) \eta y)\right][\theta x-(\theta x+y(1-\theta))(\eta \theta+\gamma(1-\eta))]}{[\theta x+(1-\theta) y][1-(\theta \eta x+\eta y(1-\theta))]}<0 \quad .
$$

Above I have already shown that $\theta x-(\theta x+y(1-\theta))(\eta \theta+\gamma(1-\eta))>0$ and $1-(\theta \eta x+\eta y(1-\theta))>0$. Then, it is left to find out when $y-\eta \theta x-\eta(1-\theta) y)<0$ holds:

$$
\begin{aligned}
y-\eta \theta x-\eta(1-\theta) y) & <0 \\
\frac{x}{y} & >\frac{1-(1-\theta) \eta}{\theta \eta} \\
\eta & <\frac{y}{\theta x+(1-\theta) y} .
\end{aligned}
$$

This means that hub-signaling makes the network entrepreneurs with a low success probability projects better off only if $\eta>\frac{y}{\theta x+(1-\theta) y}$ (given the signal structure) or $\frac{x}{y}<\frac{1-(1-\theta) \eta}{\theta \eta}$ (given the network size). 


\section{A.3 Proof of Proposition 5}

For any start-up of a network entrepreneur with a high success probability project $\mathcal{V}_{H}-\overline{\mathcal{V}}=$ $[x \hat{p}+(1-x) \tilde{p}] Y-\bar{p} Y>0$ and there are $\theta$ of them. In the same way, for any start-up of a network entrepreneur with a low success probability project, $\overline{\mathcal{V}}-\mathcal{V}_{L}=\bar{p} Y-[y \hat{p}+(1-y) \tilde{p}] Y>0$ and there are $1-\theta$ of them. Hence, the increase in the market value of the start-ups of entrepreneurs with high success probability projects due to hub-signaling is higher than the total decrease in the market value of the start-ups of entrepreneurs with low success probability projects if $\theta[x \hat{p}+(1-x) \tilde{p}-\bar{p}]>(1-\theta)[\bar{p}-y \hat{p}-(1-y) \tilde{p}]$ or alternatively if the following inequality holds.

$$
[\theta x+(1-\theta) y] \hat{p}+[\theta(1-x)+(1-\theta)(1-y)] \tilde{p}>\bar{p}
$$

By substituting for $\tilde{p}, \bar{p}$, and $\hat{p}$ into (A-7), one can get

$$
\begin{aligned}
\theta x p_{H}+(1-\theta) y p_{L} & +[\theta(1-x)+(1-\theta)(1-y)] \\
\times & \frac{[(1-x) \theta \eta+\gamma(1-\eta)] p_{H}+[(1-y)(1-\theta) \eta+(1-\gamma)(1-\eta)] p_{L}}{\eta[(1-x) \theta+(1-y)(1-\theta) \eta]+(1-\eta)}>\bar{p} .
\end{aligned}
$$

After some manipulation

$$
\theta x p_{H}+(1-\theta) y p_{L}+\frac{[(1-x) \theta \eta+\gamma(1-\eta)] p_{H}+[(1-y)(1-\theta) \eta+(1-\gamma)(1-\eta)] p_{L}}{\eta+\frac{(1-\eta)}{[\theta(1-x)+(1-\theta)(1-y)]}}>\bar{p}
$$

or

$$
\frac{\frac{(1-\eta)\left[\theta x p_{H}+(1-\theta) y p_{L}\right]}{[\theta(1-x)+(1-\theta)(1-y)]}+[\theta \eta+\gamma(1-\eta)] p_{H}+[(1-\theta) \eta+(1-\gamma)(1-\eta)] p_{L}}{\eta+\frac{(1-\eta)}{[\theta(1-x)+(1-\theta)(1-y)]}}>\bar{p} .
$$

However, the second term on the numerator is nothing but $\bar{p}$. Therefore,

$$
\begin{gathered}
\frac{\frac{(1-\eta)\left[\theta x p_{H}+(1-\theta) y p_{L}\right]}{[\theta(1-x)+(1-\theta)(1-y)]}+\bar{p}}{\eta+\frac{(1-\eta)}{[\theta(1-x)+(1-\theta)(1-y)]}}>\bar{p} \\
\frac{(1-\eta)\left[\theta x p_{H}+(1-\theta) y p_{L}\right]+[\theta(1-x)+(1-\theta)(1-y)] \bar{p}}{[\theta(1-x)+(1-\theta)(1-y)] \eta+(1-\eta)}>\bar{p}
\end{gathered}
$$

or

$$
\begin{aligned}
(1-\eta)\left[\theta x p_{H}+(1-\theta) y p_{L}\right]+[\theta(1-x)+(1-\theta) & (1-y)] \bar{p} \\
& >\bar{p}[[\theta(1-x)+(1-\theta)(1-y)] \eta+(1-\eta)]
\end{aligned} .
$$

Arranging gives

$$
\begin{aligned}
(1-\eta)\left[\theta x p_{H}+(1-\theta) y p_{L}\right] & >\bar{p}[(1-\eta)-[\theta(1-x)+(1-\theta)(1-y)](1-\eta)] \\
(1-\eta)\left[\theta x p_{H}+(1-\theta) y p_{L}\right] & >\bar{p}(1-\eta)[1-\theta(1-x)-(1-\theta)(1-y)] \\
\theta x p_{H}+(1-\theta) y p_{L} & >\bar{p}[1-\theta(1-x)-(1-\theta)(1-y)] \\
\theta x p_{H}+(1-\theta) y p_{L} & >\bar{p}[\theta x+(1-\theta) y] \\
\frac{\theta x p_{H}+(1-\theta) y p_{L}}{\theta x+(1-\theta) y} & >\bar{p} \\
\hat{p} & >\bar{p} .
\end{aligned}
$$

Therefore, the right hand side of (A-7) is always greater than the left hand side. 


\section{References}

[1] Acs, Z., D. Audretsch, P. Braunerhjelm, and B. Carlsson. 2005. Growth and entrepreneurship: an empirical assessment. CEPR Discussion Paper 5409.

[2] Arnott, R., and J. Stiglitz. 1991. Moral hazard and nonmarket institutions: dysfunctional crowding out or peer monitoring. American Economic Review 81: 179-190.

[3] Bala, V., and S. Goyal. 2000. A noncooperative model of network formation. Econometrica 68: $1181-1229$

[4] Bates, T. 2005. Analysis of young, small firms that have closed: delineating successful from unsuccessful closures. Journal of Business Venturing 20: 343-258.

[5] Brandt, N. 2004. Business dynamics and policies. OECD Economic Studies 38: 9-36.

[6] Campbell, T., and W. Kracaw. 1980. Information production, market signaling, and the theory of financial intermediation. Journal of Finance 35: 863-882.

[7] European Commission. 2003. Green Paper: Entrepreneurship in Europe. Brussels.

[8] Glaeser, E, H. Kallal, J. Scheinkman, and A. Shleifer. 1992. Growth in cities. Journal of Political Economy 100: 1126-1152.

[9] Headd, B. 2003. Redefining business success: distinguishing between closure and failure. Small Business Economics 21: 51-61.

[10] Inci, E. 2005. A model of R\&D tax incentives. Boston College - Economic Department Working Paper 597.

[11] Inci, E. 2006. Occupational choice and the quality of entrepreneurs. mimeo.

[12] Krugman, P. 1991. Increasing returns and economic geography. Journal of Political Economy 99: 483-499.

[13] Lamoreaux, N., M. Levenstein, and K. Sokoloff. 2004. Financing invention during the Second Industrial Revolution: Cleveland, Ohio, 1870-1920. NBER Working Paper 10923.

[14] OECD. 2006. Structural and Demographic Business Statistics 1996-2003. Paris: OECD Publishing.

[15] Petersen, M., and R. Rajan. 1994. The benefits of lending relationships: evidence from small business data. Journal of Finance 49: 3-37.

[16] Stiglitz, J., and A. Weiss. 1981. Credit rationing in markets with imperfect information. American Economic Review 71: 393-410. 